\title{
Healed cracks in iceberg ice
}

\author{
Paul D. BARRETTE, IAn J. JORDAAN \\ Ocean Engineering Research Centre, Faculty of Engineering and Applied Science, Memorial University of Nerwfoundland, \\ St Fohn's, Nerefoundland A1B 3X5, Canada \\ E-mail:paulb@engr.mun.ca
}

\begin{abstract}
A noticeable trait of iceberg ice is the presence of several sets of planar features cross-cutting each other at various angles. Close-up views of these features show that they consist of an array of individual air inclusions that differ in size, shape and spatial distribution. In none of the cases resolvable at the scale of our observations were these inclusions physically linked to form a continuous fracture plane, although they may have originated as such. All postdate the formation of ice veins.
\end{abstract}

\section{INTRODUCTION}

Scale effects are very important in determining the loads exerted by icebergs on offshore structures. These effects correspond to a decrease in average pressure with increase in contact area (e.g. Lavrov, 1973; Johnson and Benoit, 1987) and are related to brittle failure of the ice. The latter is, in turn, affected by the internal structure: crystal shape, size and orientation, air inclusions, layering, and ice veins.

Another conspicuous feature characterizing iceberg ice is what appears to be fracture patterns (Fig. 1). These are readily noticeable in hand specimens, and commonly occur as a number of sets of fractures cross-cutting each other at various angles. Although they are not crevasses or open fissures, they may represent a pre-existing structural flaw that is likely to promote crack propagation. There is currently little information available on these features. Ragle and others (1964) describe glacial ice in cores extracted from the Ward Hunt Ice Shelf in northernmost Canada. Healed fractures and faults were noted from the presence of recrystallized, elongated grains or "planar orientations of sheets of bubbles marking the 'ghost' fracture" (p. 50). Gammon and others (1983) looked at porosity, internal cracks and grain structure in five grounded icebergs, and reported cracks that apparently occurred after calving. A number of other studies have provided a physical description of iceberg ice (Arockiasamy and others, 1983; Jeffries and others, 1990, 1991; Poplin and Ralston, 1992; Masterson and others, 1993; Gagnon and Gammon, 1995; Barrette and Sinha, 1996), but they have not addressed the nature of these planar features. The purpose of this paper is to provide additional information on this subject.

\section{IGE PREPARATION AND PHOTOGRAPHY}

The iceberg ice used in these investigations was purchased from an iceberg-harvesting company in St John's, and was collected from an iceberg grounded near the northeastern coastline of Newfoundland in spring 2000. The ice was delivered to us in blocks of irregular shape, averaging $500 \mathrm{~mm}$ in maximum dimension. The "double-microtoming" technique of Sinha (1977) was used to prepare thin sections of the ice, with the difference that we chose to produce thicker sections (about $10 \mathrm{~mm}$ ) in order to better decipher the internal structure of the ice. The observations were made on approximately 20 sections obtained from various blocks.

Photographs of these sections were taken between crosspolarized filters or in plain transmitted light, with and without light reflected from one side (to bring out free surfaces such as cracks and bubbles). A macro-lens and a bellows focusing attachment allowed magnifications up to $15 \times$.

\section{OBSERVATIONS}

The internal structure did not show a large variation in texture or grain-size. It had a typical glacial texture, with interlocking grains and serrated boundaries (Fig. 1). The longest dimension of all crystals was, on average, approximately $10 \mathrm{~mm}$. The largest grain encountered exceeded $50 \mathrm{~mm}$. Evidence of grain elongation was observed in only one thin section. Air inclusions (bubbles) were abundant in all specimens. In cross-sections, the bubbles were either spherical, ovoid or had an irregular shape. An average density of $0.895 \mathrm{~g} \mathrm{~mL}^{-1}$ was obtained from 17 specimens (Barrette and Jordaan, in press). The size of the air inclusions ranged from a fraction of a millimetre (below the resolution of our observations) to a maximum of $5 \mathrm{~mm}$. The elongated bubbles were up to several millimetres in length, with a preferred orientation varying from weak to very distinct.

Ice veins varying in thickness from a few millimetres to a maximum of about $30 \mathrm{~mm}$ were common. Identified by their low air content, they were therefore less opaque than the surrounding ice (Fig. 1). In hand specimens and when observed on the surface of an iceberg, these veins are normally blue in colour against a white matrix. The occurrence of a layer of air inclusions at equal distance from the walls of the vein was also typical. All veins were planar, with the exception of one that displayed a few tight folds.

\section{Planar features}

Figure 2 shows a close-up view of a few sets of planar features crossing each other at various angles. The width of 

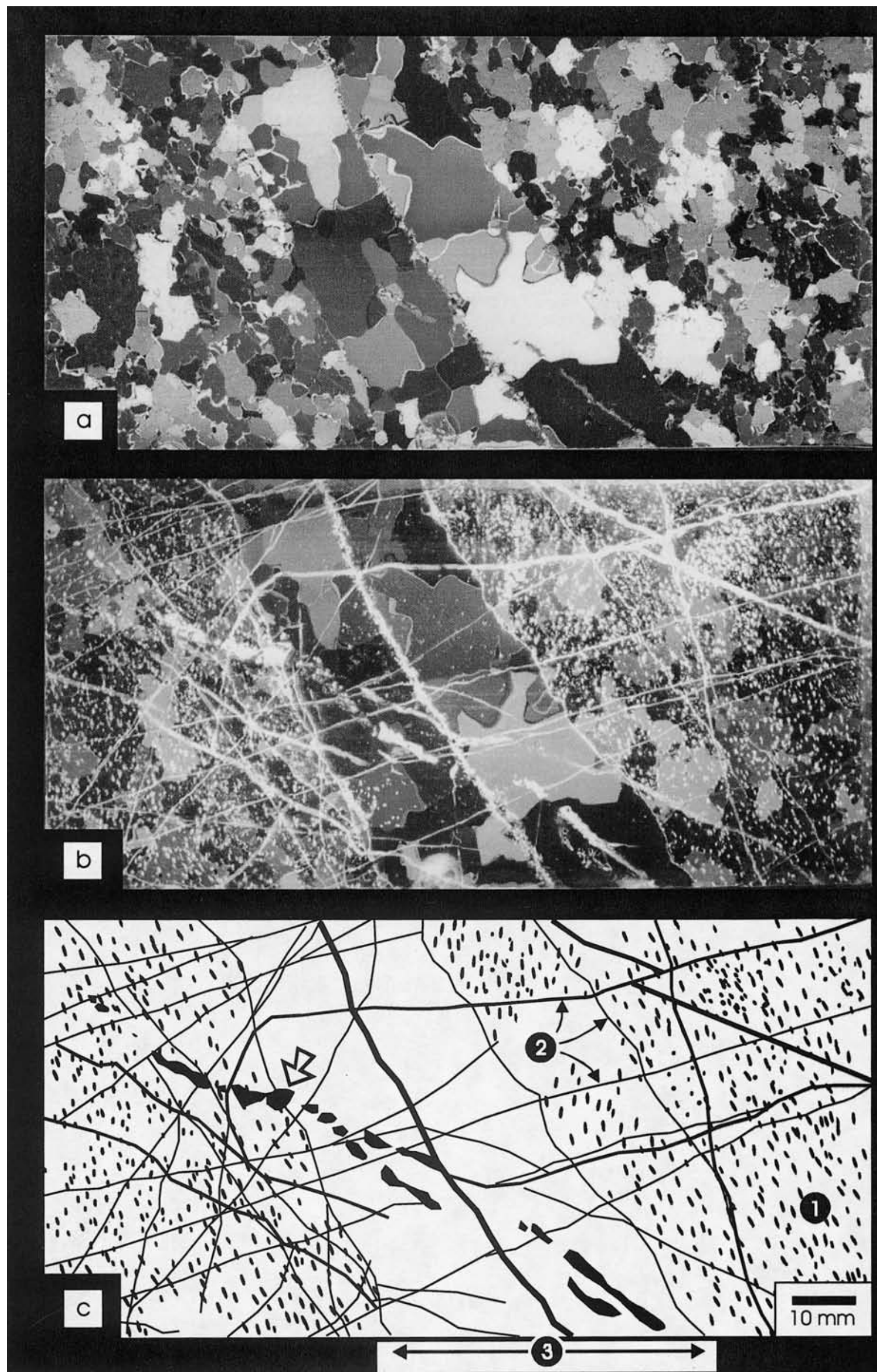

Fig. 1. (a) Thin section of iceberg ice viewed under cross-polarized light. (b) The same section, with the addition of side-reflected light. (c) Schematic diagram outlining the features in (b). These are divided into: (1) air inclusions, mm to sub-mm in size; (2) planar features (linear in the section) of various orientations and thicknesses; and (3) ice veins, here seen in the centre of the section and enclosing crystals that are larger in size than those in the surrounding ice. The small arrow near the centre of the photograph points to a particularly thick planar feature defined by the alignment of relatively large air bubbles. 


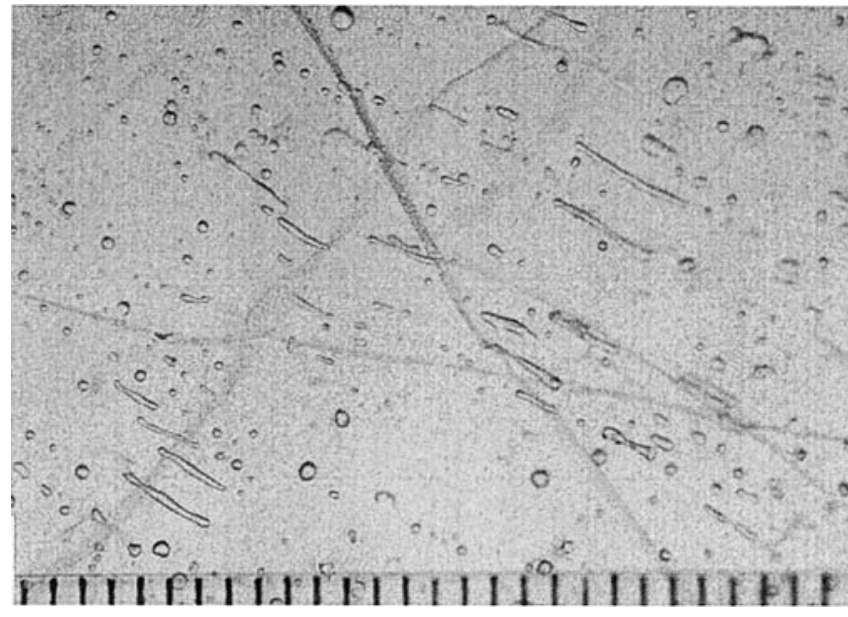

Fig. 2. Photograph of a thin section under plain transmitted light. Scale in mm. There is a criss-crossing of thin planar features.

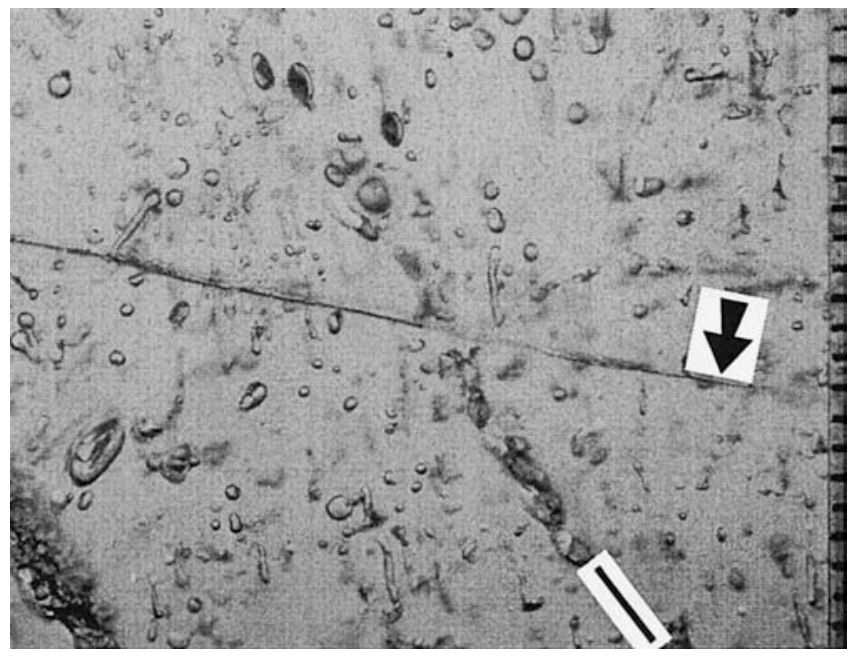

Fig. 3. Photograph of a thin section under plain transmitted light. Scale in mm. An alignment of millimetre-sized bubbles is indicated by the linear marker on the photograph. A recent crack (produced in the laboratory) is shown by an arrow.

these features as they appear on the photographs is that of their projection onto the plane of observation. The shallower the inclination with respect to this plane (indicated by a strike-and-dip symbol in Figures 4-7), the wider they appear. They vary in true thickness from a thin hairline surface to considerably thicker planar zones (up to $3-4 \mathrm{~mm}$ ).

The thickest planar features are the most conspicuous at the scale of the hand specimen. They consist of millimetresized air bubbles which, as seen in thin section, are aligned in, but sparsely distributed along, that plane (Figs 1 and 3). Thinner planes consist of planar arrays of much smaller air bubbles with a clearly defined spherical shape (Fig. 4). Their distribution varies from random to orderly in a series of rows. Some of the thinnest planes (Fig. 5), the details of which could not be deciphered at the resolution used in this study, resemble the recent crack shown in Figure 3. Figures 6 and 7 show two intersecting planar features. A displacement at the intersection of two surfaces, that would have indicated lateral slip along the more recent surface, has never been clearly observed. Thus, these are not fault surfaces but are, rather, extensional in nature.

All planar features are seen to cross-cut the ice veins, indicating that the former postdate the latter. It is interesting to note that the folded vein referred to above is cross-cut by another ice vein, which itself is cross-cut by several planar

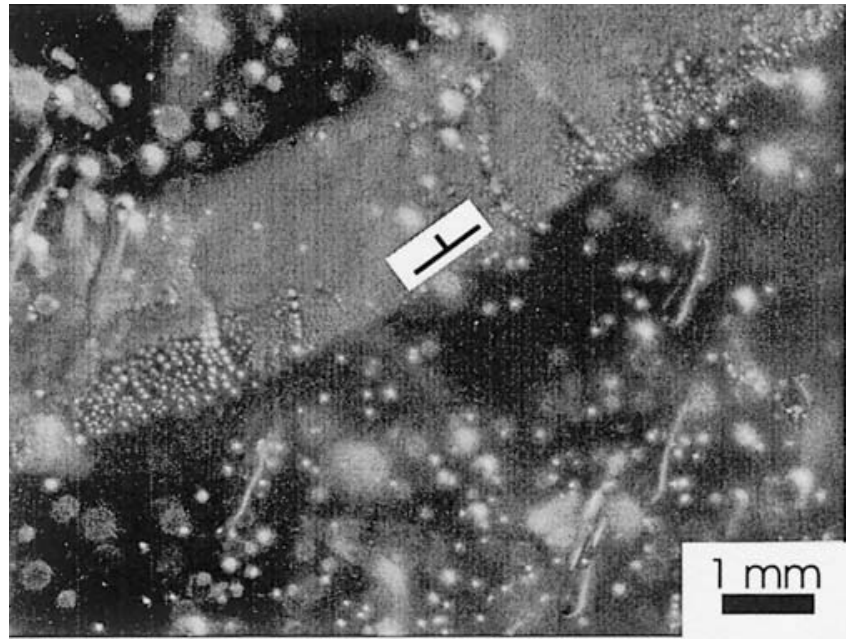

Fig. 4. Photograph of a thin section with side-reflected light only. A planar feature, with a moderate incline towards the upper left, is a two-dimensional array of spherical air bubbles.

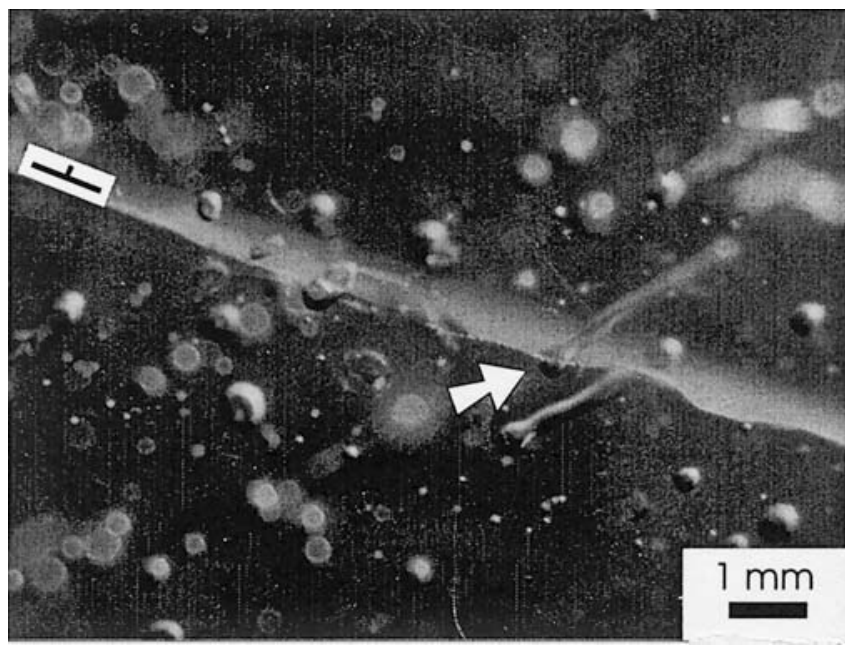

Fig. 5. Photograph of a thin section with side-reflected light only. Dipping more steeply toward the upper right is a planar feature along which very small air inclusions can be seen only locally along its length. The remaining part of the feature cannot be resolved at the magnification used in this study and resembles the recent fracture plane in Figure 3. The white arrow points to the intersection between this planar feature and an elongated air bubble.

features. This indicates that a sequence of multiple events has affected the ice over time.

\section{DISGUSSION}

Various explanations have been offered for the formation of bubble-free ice layers, or "blue ice", in glaciers. These include ice glands and lenses resulting from percolation of meltwater (Hooke and Hudleston, 1978), infilling of water in crevasses resulting from down-faulting (Hambrey, 1975), recrystallization of water-soaked materials (Allen and others, 1960), dilational fractures generated as a result of shear stresses (Hudleston, 1989), and "freezing of water ponded in moulin or other cavities on the ice surface" (Allen and others, 1960, p.606). The central layer of air inclusions suggests syntaxial growth (Ramsay and Huber, 1983, p. 241), whereby ice crystals grew from the walls toward the centre of the vein, and the dissolved air was pushed ahead of the freezing front. 


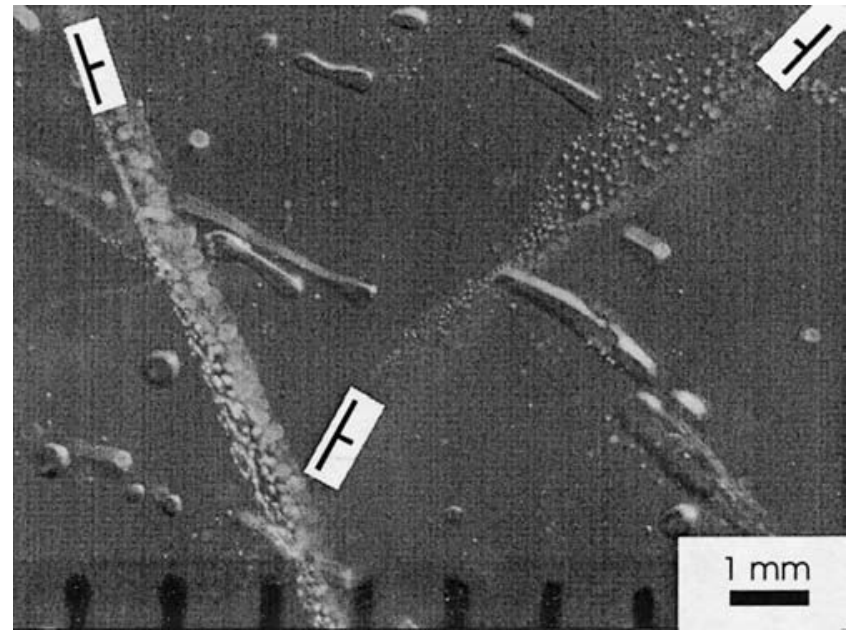

Fig. 6. Photograph of a thin section with side-reflected light only. There is a cross-cutting relationship between the planar feature with a moderate dip toward the right, and another varying from a shallow dip towards the upper left to a moderate dip towards the lower right.

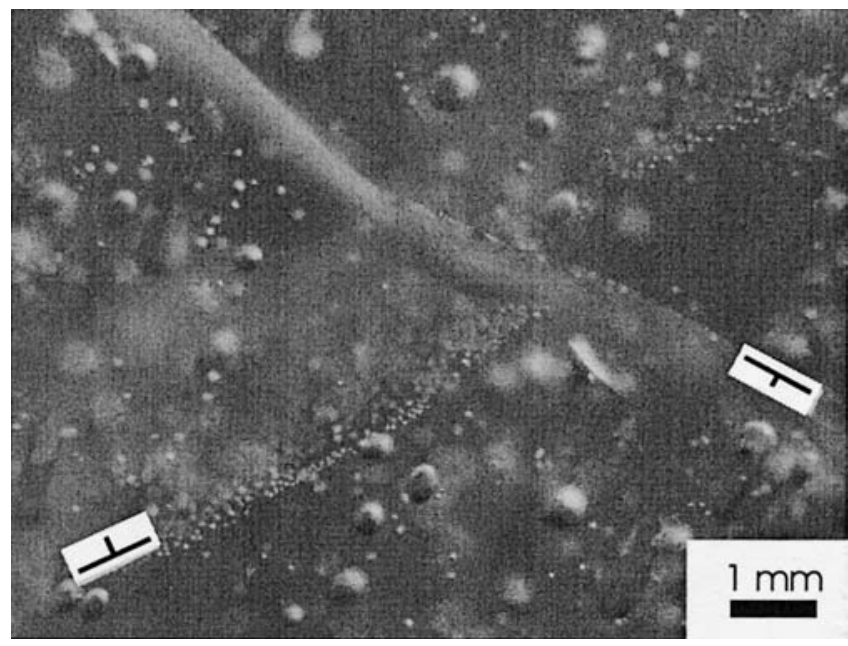

Fig. 7. Photograph of a thin section with side-reflected light only. This is another example of cross-cutting between two planar features, both defined by networks of air bubbles of different sizes.

Planar features were found in virtually all thin sections that were examined as part of this study. They occurred in various orientations and thickness, and were manifested as planar networks of individual air inclusions. The thicker planar features had large bubbles that were more widely distributed. On the other hand, very thin planar features were made up of networks of smaller, more closely spaced air bubbles.

In none of the cases we observed were these inclusions physically linked to form undisturbed, genuine free surfaces, that is, a crack. This may be the case, however, for the thinnest planes, which could not be resolved at the scale of our observations. Moreover, there appears to be a continuum in morphology from the thickest to the thinnest plane (Fig. 8). This raises the possibility that the latter evolved into the former.

Evidence that a crack can lead to the development of a network of air bubbles was provided by Nakawo and Wakahama (1981). Two mechanisms may be envisaged for the increase in size of gas inclusions in a crystalline matrix (e.g. Trinkaus, 1989; Fichtner and others, 1991). One is the migration and coalescence of existing inclusions. A non-hydrostatic stress, such as that causing glacial flow, and a large amount of strain could be required for this process to take place (Weertman,

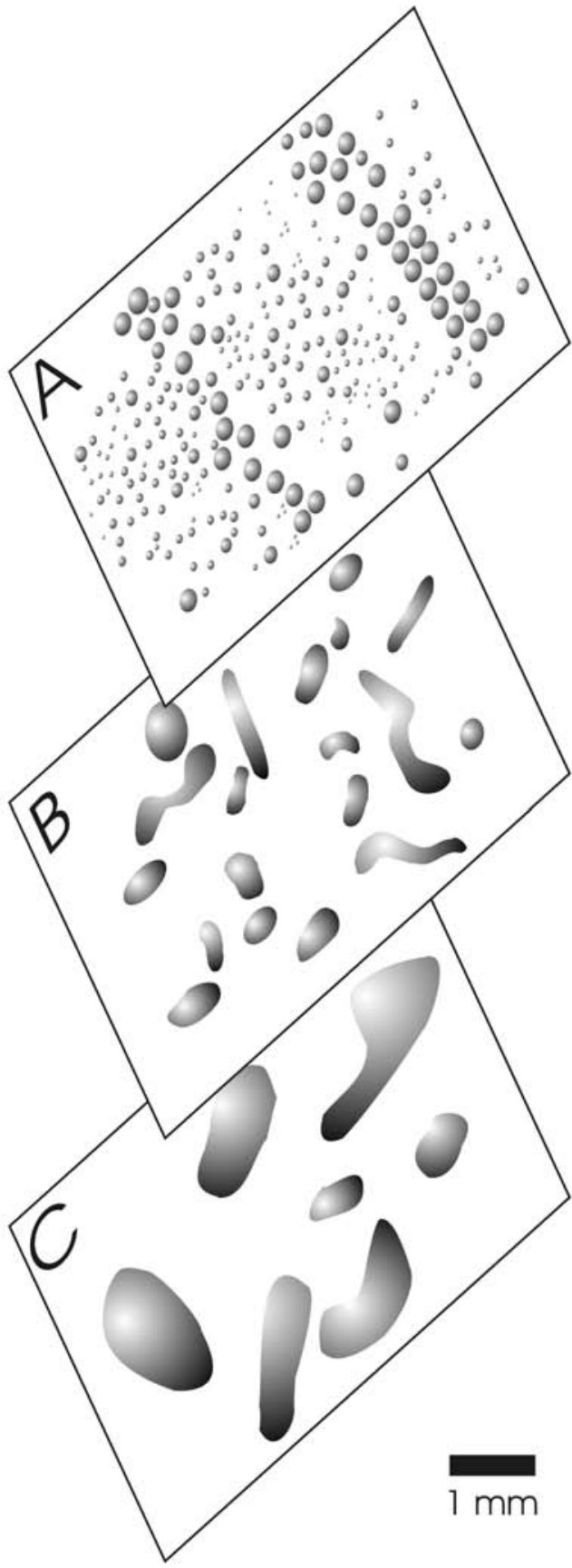

Fig. 8. Morphology of the planar features observed during this study. The thinnest plane resolvable is defined by an array of spherical air inclusions $(A)$. In other cases, the inclusions are larger and have a more irregular shape $(B)$. The most conspicuous planar features seen in hand specimens consist of much larger, irregularly shaped, air inclusions, sparsely distributed across the plane $(C)$.

1968). The other mechanism is bubble-to-bubble gas transfer, also known as Ostwald ripening (Markworth, 1972; Fichtner and others, 1991). Either process will lead to crack healing. Such cracks would be analogous to joints in rocks, in that they would be caused by the release of elastically stored stresses (Ramsay and Huber, 1983, p. 235). Thermal gradients in the ice and wave or tide activity are potential sources of such stresses.

Some of the earlier ice veins may have developed prior to calving. This is undoubtedly the case for the folded vein. The later ones, however, may have formed afterward. All healed fracture surfaces, on the other hand, would have to develop late in the history of the ice, either shortly before iceberg calving or afterward. Otherwise, they would have been affected by deformation during glacial flow. It is con- 
ceivable that the ice veins and the healed fracture surfaces we observed in this study were generated before and after calving, respectively. This would explain why the fracture surfaces all appear to have occurred later than the veins.

A test program, involving beam bending of the ice described in the present study, was conducted at Memorial University to see if and how the planar features affected flexural strength (Barrette and Jordaan, www.chc.nrc.ca/english/ Cold\%20Regions/PERD, Report 4-78). The results were inconclusive. However, they did suggest an increase in strength with a decrease in grain-size and a decrease in the amount of air inclusions.

\section{CONGLUSION}

Icebergs contain planar features that look like fracture patterns to the unaided eye. Close-up views of these features show that they are defined by a planar network of air inclusions varying in size and spatial distribution. There may be a continuum between the thinner features, closely resembling a fracture plane, and the thickest ones, which are made up of coarser, more sparsely distributed air inclusions. One possibility is that the former evolved into the latter by the progressive increase in size of the air inclusions occurring along the plane, through migration and coalescence or through a process known as Ostwald ripening. Either process results in what is referred to as crack healing. Cross-cutting relationships consistently indicate that the healed fracture surfaces we observe in our specimens postdate the formation of ice veins. These fractures are thought to have formed either shortly before iceberg calving, or afterward.

\section{ACKNOWLEDGEMENTS}

The experimental work presented in this report was done with the assistance of T. Mackey. S. J. Jones allowed us access to the Institute for Marine Dynamics, National Research Council of Canada, St John's, where A. Bugden provided the necessary logistical support. Funding from the Natural Sciences and Engineering Research Council of Canada (NSERC), the Government of Canada through the Program on Energy Research and Development (PERD), and the Canada-Newfoundland Offshore Development Fund is gratefully acknowledged. The manuscript benefited from comments by two anonymous referees and the assistance of M. A. Lange as Scientific Editor.

\section{REFERENCES}

Allen, C. R., W. B. Kamb, M. F. Meier and R. P. Sharp. 1960. Structure of the lower Blue Glacier, Washington. F. Geol., 68(6), 601-625.
Arockiasamy, M., H. El-Tahan, A. S. J. Swamidas, W. E. Russell and D.V. Reddy. 1983. Semi-submersible response to bergy bit impact. In Proceedings of the RINA Engineering Group International Symposium on "Semi-Submersibles: the New Generation”, 17-18 March 1983, London, England. London, Royal Institute of Naval Architects. (Paper 14.)

Barrette, P. D. and I. J. Jordaan. In press. Pressure-temperature effects on the compressive behaviour of laboratory grown and iceberg ice. Cold Reg. Sci. Technol.

Barrette, P. D. and N. K. Sinha. 1996. Crystallographic characterization of a core from the Ward Hunt Ice Shelf, Canada. In Agrawal, K. C., ed. Proceedings of the International Symposium on Snow and Related Manifestations, SNOWSTMP 94, Manali, 26-28 September 1994. Manali, India, Snow and Avalanche Study Establishment, 114-124.

Fichtner, P. F. P., H. Schroeder and H. Trinkaus. 1991. A simulation study of Ostwald ripening of gas bubbles in metals accounting for real gas behaviour. Acta Metall., 39(8), 1845-1852.

Gagnon, R. E. and P. H. Gammon. 1995. Characterization and flexural strength of iceberg and glacier ice. F. Glaciol., 41 (137), 103-111.

Gammon, P., R. Gagnon, W. Bobby and W. E. Russell. 1983. Physical and mechanical properties of icebergs. In OTC83, 15th Annual Offshore Technology Conference, 2-6 May 1983, Houston, Texas. Proceedings. Vol. 1, 143-150. (OTC Paper 4459.)

Hambrey, M. J. 1975. The origin of foliation in glaciers: evidence from some Norwegian examples. F. Glaciol., 14(70), 181-185.

Hooke, R. LeB. and P. J. Hudleston. 1978. Origin of foliation in glaciers. F. Glaciol., 20 (83), 285-299.

Hudleston, P. J. 1989. The association of folds and veins in shear zones. F. Struct. Geol., $11(8)$, 949-957.

Jeffries, M. O., N. K. Sinha and W. M. Sackinger. 1990. Deformation of natural ice island under constant strain rate uniaxial compression. In IAHR. Symposium on Ice, Espoo, Finland, August 20-24, 1990. Proceedings. Vol. 1. Espoo, Helsinki University of Technology, 238-251.

Jeffries, M. O., H.V. Serson, H. R. Krouse and W. M. Sackinger. 1991. Ice physical properties, structural characteristics and stratigraphy in Hobson's Choice Ice Island and implications for the growth history of East Ward Hunt Ice Shelf, Canadian High Arctic. 7. Glaciol., 37(126), 247-260.

Johnson, R. G. and J. R. Benoit. 1987. Iceberg impact strength. In Proceedings, 19th Annual Offshore Technology Conference, 27-30 April 1987, Houston, Texas. Vol. 4, 417-423. (OTC Paper 5599.)

Lavrov, V.V. 1973. Scale effects as indication of ice-breaking mechanism. In Yakovlev, G. N., ed. Studies in ice physics and ice engineering. Jerusalem, Israel Program for Scientific Translations, 26-32. (Proceedings 300.)

Markworth, A. J. 1972. On the coarsening of gas-filled pores in solids. Metall. Trans., 4, 2651-2656.

Masterson, D. M., D. E. Nevel, R. G. Johnson, J. J. Kenny and P. A. Spencer. 1993. The medium scale iceberg impact test program. In IAHR 92. 11th International Symposium on Ice, Banff, Alberta, Canada, Fune 15-19, 1992. Proceedings. Vol. 2. Edmonton, Alta, University of Alberta. Department of Civil Engineering, 930-966.

Nakawo, M. and G. Wakahama. 1981. Preliminary experiments on the formation of elongated air bubbles in glacier ice by stress. 7. Glaciol., $27(95), 141-146$

Poplin, J. P. and T. D. Ralston. 1992. Physical and mechanical properties of Hobson's Choice Ice Island cores. Cold Reg. Sci. Technol., 20 (2), 207-223.

Ragle, R. H., R. G. Blair and L. E. Persson. 1964. Ice core studies of Ward Hunt Ice Shelf, 1960. 7. Glaciol., 5(37), 39-59.

Sinha, N. K. 1977. Dislocations in ice as revealed by etching. Philos. Mag., 36(6), 1385-1404.

Trinkhaus, H. 1989. The effect of internal pressure on the coarsening of inert gas bubbles in metals. Scripta Metall., 23, 1773-1778.

Weertman, J. 1968. Bubble coalescence in ice as a tool for the study of its deformation. F. Glaciol., 7(50), 155-159. 